\title{
Evaluating the impact of the Baby-Friendly Hospital Initiative on breast-feeding rates: a multi-state analysis
}

\author{
Summer Sherburne Hawkins ${ }^{1, *}+$, Ariel Dora Stern ${ }^{2}$, Christopher F Baum ${ }^{3,4}$ and \\ Matthew W Gillman ${ }^{5}$ \\ 'Boston College, Graduate School of Social Work, McGuinn Hall, 140 Commonwealth Avenue, Chestnut Hill, \\ MA 02467, USA: ${ }^{2}$ Harvard Kennedy School of Government, Cambridge, MA, USA: ${ }^{3}$ Boston College, Chestnut \\ Hill, MA, USA: ${ }^{4}$ Deutsches Institut für Wirtschaffforschung (DIW Berlin), Berlin, Germany: ${ }^{5}$ Harvard Medical \\ School and Harvard Pilgrim Health Care Institute, Boston, MA, USA
}

Submitted 20 August 2013: Final revision received 17 December 2013: Accepted 19 December 2013: First published online 14 March 2014

\begin{abstract}
Objective: To evaluate the impact of the Baby-Friendly Hospital Initiative (BFHI) on breast-feeding initiation and duration overall and according to maternal education.

Design: Quasi-experimental study using data from five states (Alaska, Maine, Nebraska, Ohio, Washington) that participated in the Pregnancy Risk Assessment Monitoring System from 1999 to 2009. Using differences-in-differences models that included year and hospital fixed effects, we compared rates of breast-feeding initiation and duration (any and exclusive breast-feeding for $\geq 4$ weeks) before and after BFHI accreditation between mothers who gave birth in hospitals that were accredited or became accredited and mothers from matched non-BFHI facilities. We stratified analyses into lower and higher education groups.

Setting: Thirteen BFHI hospitals and nineteen matched non-BFHI facilities across five states in the USA.

Subjects: Mothers ( $n$ 11723) who gave birth in BFHI hospitals and mothers ( $n$ 13604) from nineteen matched non-BFHI facilities.

Results: Although we did not find overall differences in breast-feeding initiation between birth facilities that received BFHI accreditation compared with nonBaby-Friendly facilities (adjusted coefficient $=0.024 ; 95 \%$ CI $-0 \cdot 00,0.51$ ), breast-feeding initiation increased by 3.8 percentage points among mothers with lower education who delivered in Baby-Friendly facilities $(P=0 \cdot 05)$, but not among mothers with higher education (adjusted coefficient $=0 \cdot 002 ; 95 \% \mathrm{CI}-0 \cdot 04,0 \cdot 05$ ). BFHI accreditation also increased exclusive breast-feeding for $\geq 4$ weeks by 4.5 percentage points $(P=0.02)$ among mothers with lower education who delivered in BFHI facilities.

Conclusions: By increasing breast-feeding initiation and duration among mothers with lower education, the BFHI may reduce socio-economic disparities in breast-feeding.
\end{abstract}

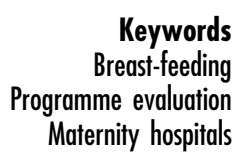

Keywords Programme evaluation Maternity hospitals
Steady gains in breast-feeding initiation and duration among US mothers have resulted in the highest levels of breast-feeding seen in over 30 years $^{(1,2)}$. Although $77 \%$ of mothers are initiating breast-feeding, only $16 \%$ are achieving the American Academy of Pediatrics' recommendation of exclusive breast-feeding for the first 6 months $^{(2,3)}$. Moreover, racial and socio-economic disparities persist ${ }^{(1,4-6)}$; black mothers are less likely to start and continue breast-feeding than white and Hispanic mothers ${ }^{(5,6)}$. Lower maternal education is also one of the

$\dagger$ This work was carried out when Dr S.S. Hawkins was based at Harvard School of Public Health, Boston, MA, USA. strongest predictors of not initiating breast-feeding and early discontinuation ${ }^{(5,7,8)}$.

Current US practices to promote breast-feeding are not ideal. The 2011 US Surgeon General's Call to Action to Support Breastfeeding identified hospital policies and clinical practices as important barriers for many women to successfully start breast-feeding and continue after discharge ${ }^{(5)}$. Results from the survey of Maternity Practices in Infant Nutrition and Care (mPINC) conducted by the Centers for Disease Control and Prevention in 2011 indicated that the average score for US hospitals and birth centres was 70 out of 100 points on a measure of practices to support breast-feeding ${ }^{(9)}$. The US Surgeon 
General's report listed implementation of the Baby-Friendly Hospital Initiative (BFHI) as the first strategy to achieve the goal of ensuring that maternity care practices are fully supportive of breast-feeding ${ }^{(5)}$.

The BFHI was established by the WHO and UNICEF in 1991 and evidence-based guidelines, Ten Steps to Successful Breastfeeding, were published to promote, protect and support breast-feeding within the birth facility and after $^{(10,11)}$. While more than 20000 hospitals and birth centres in 156 countries had been designated as BabyFriendly by $2009^{(12)}$, there were only $158 \mathrm{BFHI}$ facilities in the USA as of January $2013^{(11)}$. Increasing the proportion of US births in facilities that support breast-feeding is a public health priority ${ }^{(3,5,13-15)}$.

Despite the breadth of evidence on BFHI internationally ${ }^{(16-22)}$, research in the USA has been limited. The majority of research in the USA has been crosssectional. Overall, these studies found that more BFHI hospital practices were associated with higher breast-feeding initiation and continuation ${ }^{(7,23-27)}$. Some longitudinal data emanate from a single hospital, Boston Medical Center, an inner-city US hospital serving a predominantly lowincome and black population that became Baby-Friendly in 1999. A series of before-after studies has demonstrated increases in breast-feeding initiation ${ }^{(28)}$ and sustained levels of breast-feeding initiation a few years after accreditation $^{(29)}$ as well as breast-feeding rates at 6 months that were consistent with national levels ${ }^{(30)}$. Before-after studies do not include a control group nor do they take into account increases in breast-feeding over time. The only randomized controlled trial of the BFHI has been conducted in Belarus ${ }^{(18)}$, a country with breast-feeding rates and a health-care system that are very different from those in the USA.

To overcome the limitations of previous research, we conducted a longitudinal study of the effects of BFHI accreditation on breast-feeding rates over an 11-year period among 25000 mothers giving birth in thirty-two hospitals from five states. Our aim was to evaluate the impact of the BFHI on breast-feeding initiation and duration overall and according to education level.

\section{Methods}

The Pregnancy Risk Assessment Monitoring System (PRAMS) is a surveillance project of the Centers for Disease Control and Prevention and state health departments to monitor the health and health behaviours of mothers before, during and after pregnancy ${ }^{(31)}$. Although twenty-eight states currently participate in PRAMS, only twelve states have data available from 1999/2000 through 2009. Participating states randomly sample between 1000 and 3400 mothers per year from birth certificate records, with over-sampling of mothers at higher risk for adverse pregnancy outcomes (response rate at least 65\% across states and years) ${ }^{(31)}$. Mothers are initially surveyed through mailed questionnaires, standardized across all states, starting at 2 months through 6 months postpartum and followed-up by telephone calls to increase response. On average, mothers respond 4 months postpartum.

We included Alaska, Maine, Nebraska, Ohio and Washington in the present study because these states had at least one birth facility receive BFHI accreditation during 1999 through 2009, when PRAMS data were collected, and the state released hospital identifiers. The years of PRAMS data varied across states as did the timing of hospitals' BFHI accreditation (Table 1). Of the 75339 mothers with information available on breast-feeding initiation for years 1999-2009, we excluded 1548 mothers who gave birth at home or in an unknown location and a further 8413 who gave birth in facilities with fewer than 100 births over the study period. The final sample included 11723 mothers who gave birth in thirteen hospitals that received accreditation prior to 1999 or became BFHI accredited during 1999 through 2009 and 13604 mothers from nineteen matched non-BFHI birth facilities (40051 mothers were excluded due to matching).

\section{Breast-feeding initiation and duration}

On PRAMS questionnaires mothers reported whether they ever breast-fed or pumped breast milk and fed it to their baby after delivery. We defined breast-feeding initiation as a response of yes. At the time of the questionnaire, mothers were asked if they were still breast-feeding or feeding their baby pumped milk and if not, the number of weeks or months they did so. We defined breast-feeding duration as continuing to breast-feed for 4 weeks or more. Mothers were also asked the baby's age in weeks or months when he/she was first fed any liquids or solid food besides breast milk since birth, such as formula, baby food, juice, cow's milk or water. We defined exclusive breast-feeding as consuming only breast milk for 4 weeks or more.

\section{BFHI accreditation}

We located information on the month and year of BFHI accreditation from Baby-Friendly USA, the accrediting body for the BFHI in the USA ${ }^{(11)}$. Baby-Friendly accreditation in the USA is the culmination of a lengthy process to achieve both the Ten Steps to Successful Breastfeeding ${ }^{(10,11)}$ and the International Code of Breast-milk Substitutes ${ }^{(32)}$. In the PRAMS data we identified thirteen BFHI facilities and coded each mother as giving birth before or after accreditation.

\section{Sociodemographic characteristics}

Information on infants' birth certificates is linked with PRAMS survey data. The birth certificates contain data on maternal race/ethnicity, years of education, age, marital status, the number of live births and the number of 
Table 1 Characteristics of participating BFHI hospitals ( $n$ 13), matched birth facilities ( $n$ 19) and women ( $n 25327$ ); Pregnancy Risk Assessment Monitoring System, 1999-2009, five US states (AK, ME, NE, OH and WA)

\begin{tabular}{|c|c|c|c|c|c|c|c|c|c|c|c|}
\hline & \multirow{2}{*}{$\begin{array}{c}\text { Date } \\
\text { accredited }^{*}\end{array}$} & \multirow{2}{*}{$\begin{array}{l}\text { Annual } \\
\text { no. of } \\
\text { births* }\end{array}$} & \multirow{2}{*}{$\begin{array}{c}\text { Years } \\
\text { PRAMS data } \\
\text { available }\end{array}$} & \multirow{2}{*}{$\begin{array}{l}\text { No. of babies born } \\
\text { before/after BFHI } \\
\text { accreditation }\end{array}$} & \multicolumn{3}{|c|}{ \% Race/ethnicity } & \multirow{2}{*}{$\begin{array}{l}\% \text { Education } \\
\leq 12 \text { years }\end{array}$} & \multirow{2}{*}{$\begin{array}{l}\% \text { Breast-feeding } \\
\text { initiation }\end{array}$} & \multirow{2}{*}{$\begin{array}{c}\% \text { Any } \\
\text { breast-feeding } \\
\text { for } \geq 4 \text { weeks }\end{array}$} & \multirow{2}{*}{$\begin{array}{l}\% \text { Exclusive } \\
\text { breast-feeding } \\
\text { for } \geq 4 \text { weeks }\end{array}$} \\
\hline & & & & & White & Black & Hispanic & & & & \\
\hline Alaska & & & 2000-2009 & & & & & & & & \\
\hline Hospital A & Nov 2008 & 2489 & & $3309 / 381$ & 61 & 6 & 12 & 46 & 92 & 81 & 55 \\
\hline Two matched facilities & & & & 4014 & 21 & 1 & 3 & 72 & 88 & 73 & 46 \\
\hline Maine & & & 1999-2009 & & & & & & & & \\
\hline Hospital B & Jul 1997 & 203 & & $0 / 157$ & 97 & 0.6 & 1 & 49 & 85 & 76 & 69 \\
\hline Hospital C & May 2006 & 821 & & $452 / 233$ & 96 & 2 & $0 \cdot 7$ & 49 & 73 & 59 & 46 \\
\hline Hospital D & Apr 2007 & 1162 & & $657 / 264$ & 98 & 0.2 & 0.4 & 52 & 79 & 64 & 53 \\
\hline Hospital E & Feb 2008 & 402 & & $216 / 38$ & 96 & 0.4 & 3 & 30 & 87 & 76 & 57 \\
\hline Six matched facilities & & & & 2461 & 97 & 0.9 & 1 & 40 & 78 & 66 & 50 \\
\hline Nebraska & & & 2000-2009 & & & & & & & & \\
\hline Hospital F & Jan 2001 & 3776 & & 207/1790 & 59 & 12 & 6 & 22 & 83 & 71 & 45 \\
\hline Hospital G & Sep 2008 & 1955 & & $1275 / 203$ & 50 & 9 & 10 & 37 & 78 & 65 & 45 \\
\hline Two matched facilities & & & & 3597 & 48 & 11 & 15 & 35 & 82 & 68 & 43 \\
\hline Ohio & & & 1999-2009 & & & & & & & & \\
\hline Hospital H & Sep 2003 & 967 & & $63 / 70$ & 96 & $0 \cdot 8$ & $0 \cdot 8$ & 50 & 62 & 45 & 35 \\
\hline Hospital I & Sep 2003 & 2130 & & $48 / 88$ & 69 & 24 & 1 & 38 & 73 & 57 & 44 \\
\hline Hospital J & Sep 2008 & 1918 & & $132 / 21$ & 66 & 29 & $0 \cdot 7$ & 46 & 70 & 57 & 36 \\
\hline Four matched facilities & & & & 725 & 74 & 23 & 1 & 50 & 62 & 48 & 31 \\
\hline Washington & & & 1999-2009 & & & & & & & & \\
\hline Hospital K & Sep 1996 & 2692 & & $0 / 901$ & 33 & 4 & 20 & 22 & 96 & 90 & 60 \\
\hline Hospital L & Mar 2004 & 3149 & & $337 / 309$ & 23 & 28 & 10 & 58 & 85 & 70 & 49 \\
\hline Hospital M & Sep 2009 & 1833 & & $555 / 17$ & 13 & 38 & 19 & 53 & 91 & 80 & 53 \\
\hline Five matched facilities & & & & 2807 & 23 & 15 & 18 & 41 & 91 & 78 & 48 \\
\hline
\end{tabular}

BFHI, Baby-Friendly Hospital Initiative; PRAMS, Pregnancy Risk Assessment Monitoring System

*Information from Baby-Friendly USA ${ }^{(11)}$. 
previous births. We dichotomized maternal education into $\leq 12$ years $(0-11$ years, 12 years) and $\geq 13$ years (13-15 years, 16+ years). WIC (Special Supplemental Nutrition Program for Women, Infants, and Children) status during pregnancy was self-reported on the PRAMS questionnaire.

\section{Statistical analysis}

For each Baby-Friendly hospital we identified two matched birth facilities within the same state using the 'nneighbor' program in Stata ${ }^{(33)}$. This matching technique identifies each BFHI facility's 'nearest neighbours' by computing the Euclidian distance between the standardized values of pairs of observations; in this case, using the number of births as a proxy for the size of the birth facility, the percentage of white mothers and the percentage of mothers with high education. We matched with replacement, so a non-BFHI birth facility could match with one or more Baby-Friendly hospital. All further analyses were also conducted using the Stata statistical software package version $12 \cdot 1 \mathrm{SE}$ with robust standard errors. Based on our methodological design our estimates were not intended to be state- or nationally representative, so we did not apply PRAMS survey weights.

In adjusted regression models, we examined the maternal sociodemographic characteristics associated with breast-feeding initiation among mothers in all facilities. We next examined the maternal characteristics associated with giving birth in a BFHI facility after accreditation.

For our main analysis we used differences-in-differences models to compare breast-feeding rates before and after BFHI accreditation between mothers who gave birth in hospitals that became accredited during the study period and mothers who gave birth in non-BFHI facilities. Based on an a priori hypothesis that BFHI accreditation may differentially support breast-feeding by mothers' educational attainment, we stratified the analyses into lower ( $\leq 12$ years) and higher $(\geq 13$ years) education groups.

Because BFHI accreditation takes many months, we addressed the possibility that some effects of becoming accredited could appear before the official accreditation date by conducting two additional analyses to isolate the time-specific effect of accreditation. To confirm that the timing of hospital practice changes was consistent with accreditation, we performed robustness tests that artificially indicated that BFHI accreditation occurred either 6 or 24 months prior to the actual accreditation and in the 24-month case, censored the data at the actual date of accreditation.

For all analyses we estimated OLS (ordinary least squares) regression models with year and hospital fixed effects to control for national time trends in breastfeeding ${ }^{(1)}$, and time-invariant hospital characteristics and practices. We included a variable indicating whether mothers gave birth before or after accreditation. We also included an interaction between year and whether the birth facility ever became Baby-Friendly because of differing slopes in breast-feeding over time between these types of facilities.

The coefficients on OLS models with a dichotomous outcome are interpreted as the percentage point increase in the outcome; in this case, the probability of initiating or continuing breast-feeding associated with BFHI accreditation. Throughout the paper we describe the coefficients as percentage point changes. We considered using hospital-level random effects, but because the policy change of interest occurs at the hospital level, fixed-effects models are more appropriate. We ran separate models for the three breast-feeding outcomes: breastfeeding initiation, any breast-feeding for $\geq 4$ weeks and exclusive breast-feeding for $\geq 4$ weeks.

\section{Results}

Both within and across the five states there was variation in the racial/ethnic and educational composition of the mothers attending BFHI hospitals and non-BFHI birth facilities as well as the rates of breast-feeding initiation and duration (Table 1). Breast-feeding initiation increased from 1999 through 2009 for both types of facilities (Fig. 1). On average Baby-Friendly hospitals had higher breast-feeding initiation rates than non-BFHI-accredited facilities; however, rates were similar in 2009. On average, in 2009, any breast-feeding for $\geq 4$ weeks was higher among BFHI hospitals than non-BFHI facilities $(76 \% v$. $73 \%)$ as was exclusive breast-feeding (50\%v. 42\%).

Breast-feeding initiation was socially patterned, with higher maternal education strongly associated with the likelihood of starting breast-feeding (Table 2). Breastfeeding initiation for Hispanic mothers was, on average, $7 \cdot 4$ percentage points higher than for white mothers. Older mothers also had higher breast-feeding initiation rates compared with teenage mothers. Non-married mothers and mothers on WIC during pregnancy had lower breast-feeding initiation rates than their respective counterparts.

Maternal education was also a strong correlate of giving birth in a BFHI hospital after accreditation (Table 2). For mothers with $\geq 13$ years of education there was a $2 \cdot 2$ percentage points increase in giving birth in BFHI hospitals compared with mothers with $\leq 12$ years of education. Mothers on WIC during pregnancy were also slightly more likely to give birth in a BFHI hospital after accreditation.

Although we did not find overall differences in breast-feeding initiation between hospitals that received BFHI accreditation compared with non-Baby-Friendly facilities (adjusted coefficient $=0 \cdot 024 ; 95 \%$ CI $-0 \cdot 00$, $0 \cdot 51$ ), breast-feeding initiation increased by $3 \cdot 8$ percentage 


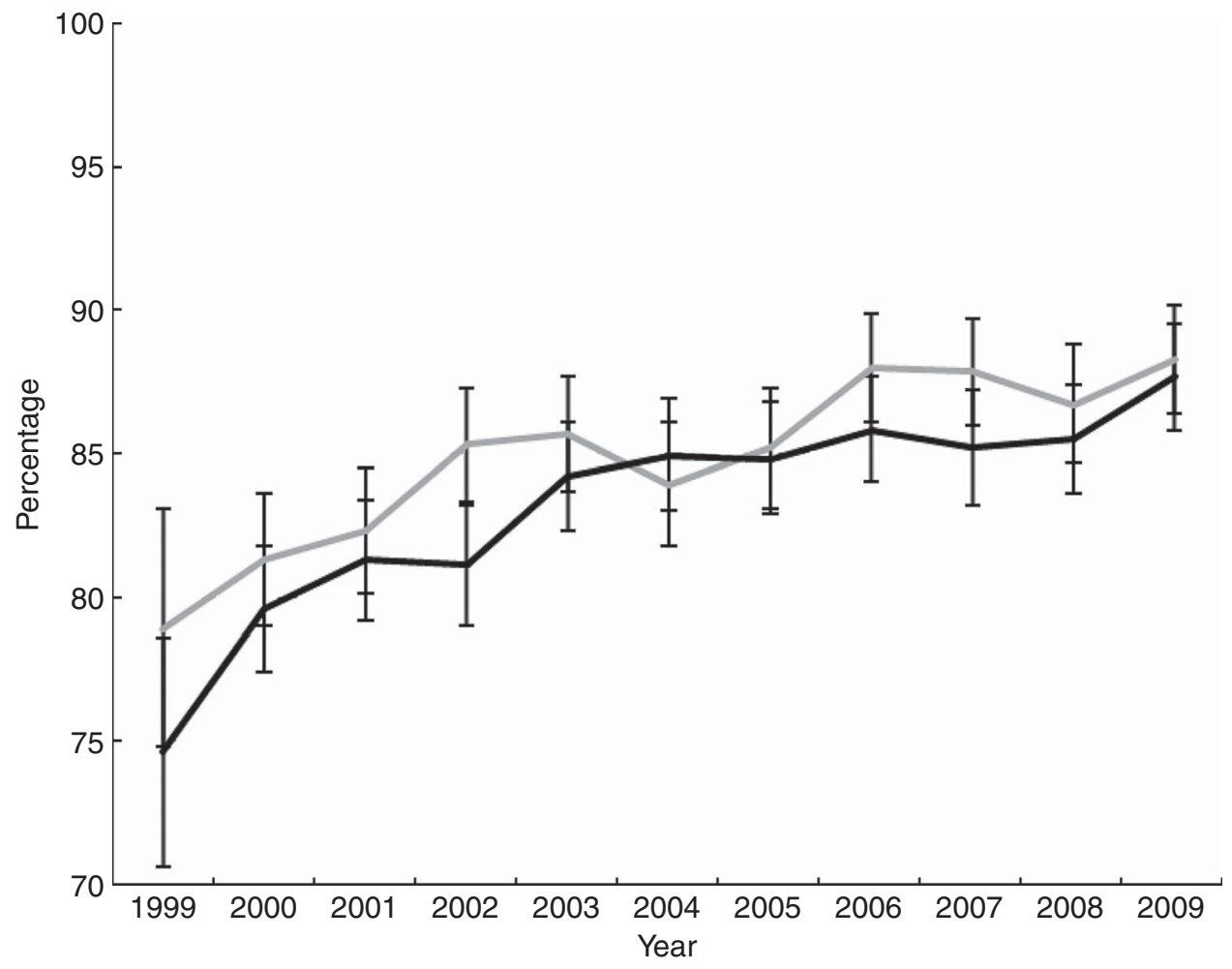

Fig. 1 Percentage of women initiating breast-feeding by Baby-Friendly status of the birth facility $(-$, BFHI; -, non-BFHI); Pregnancy Risk Assessment Monitoring System, 1999-2009, five US states (AK, ME, NE, OH and WA). Values are percentages with their $95 \%$ confidence intervals represented by vertical bars. BFHI, Baby-Friendly Hospital Initiative

points among mothers with lower education who delivered in Baby-Friendly facilities (adjusted coefficient $=$ $0 \cdot 038 ; 95 \%$ CI $-0 \cdot 00,0 \cdot 08)$, but not among mothers with higher education (adjusted coefficient $=0 \cdot 002 ; 95 \% \mathrm{CI}$ $-0 \cdot 04$, 0.05; Table 3). BFHI accreditation also increased exclusive breast-feeding for $\geq 4$ weeks by 4.5 percentage points among mothers with lower education who delivered in BFHI facilities (adjusted coefficient $=0 \cdot 045 ; 95 \% \mathrm{CI} 0 \cdot 01$, $0 \cdot 08$ ). We did not find effects of BFHI accreditation on any or exclusive breast-feeding for $\geq 4$ weeks for mothers with higher education or overall.

In analyses exploring the timing of BFHI accreditation, there was no effect of the policy either 6 months or 24 months prior to the actual date of accreditation on breast-feeding initiation (Table 3 ). We observed increased breast-feeding initiation only among mothers who gave birth in hospitals post-accreditation. These findings indicate it is unlikely that hospitals had policies in place supporting breast-feeding prior to their accreditation; rather the data provide evidence for a direct effect of BFHI accreditation on subsequent breast-feeding initiation.

We also centred the data on the date of BFHI accreditation to examine trends in breast-feeding initiation before and after for both the BFHI hospitals and their matched birth facilities. Figure 2 illustrates an overall flat trend in breast-feeding rates before accreditation and a general increase in breast-feeding initiation after accreditation, larger among Baby-Friendly hospitals. The dip in year 2 is due to the accreditation of hospitals in Ohio, which had lower rates of breast-feeding initiation than other states in the sample up until that time.

\section{Discussion}

The main finding of the present study is that although BFHI accreditation did not increase breast-feeding initiation or duration overall compared with non-BabyFriendly hospitals, it benefited mothers with lower education. We found that mothers with higher education were more likely to give birth in BFHI hospitals after accreditation, but accreditation did not increase their likelihood of initiating or continuing breast-feeding. The study highlights that policies may not affect all mothers equally and, indeed, may benefit those who are most at risk. In our sample, $78 \%$ of mothers with $\leq 12$ years of education started breast-feeding compared with $90 \%$ of mothers with $\geq 13$ years of education. For exclusive breast-feeding for $\geq 4$ weeks those differences were $41 \%$ $v .53 \%$, respectively. The estimated 3.8 percentage points increase in breast-feeding initiation and 4.5 percentage 
Table 2 Maternal sociodemographic characteristics associated with breast-feeding initiation in all facilities and birth in a BFHI-accredited facility after accreditation; Pregnancy Risk Assessment Monitoring System, 1999-2009, five US states (AK, ME, NE, OH and WA)

\begin{tabular}{|c|c|c|c|c|c|c|c|c|c|}
\hline & \multicolumn{2}{|c|}{$\begin{array}{l}\text { All mothers } \\
(n 25327)\end{array}$} & \multirow{2}{*}{$\begin{array}{l}\% \text { Breast- } \\
\text { feeding } \\
\text { initiation }\end{array}$} & \multicolumn{3}{|c|}{ Breast-feeding initiation ( $n$ 23866) } & \multicolumn{3}{|c|}{ Birth in BFHI-accredited facility ( $n$ 10775) } \\
\hline & $n$ & $\%$ & & Coefficient $^{*}$ & $95 \% \mathrm{Cl}$ & $P$ value & Coefficient $^{*}$ & $95 \% \mathrm{Cl}$ & $P$ value \\
\hline \multicolumn{10}{|l|}{ Race/ethnicity } \\
\hline White & 12830 & $50 \cdot 7$ & $83 \cdot 0$ & Ref. & - & & Ref. & - & \\
\hline Black & 2143 & $8 \cdot 5$ & $78 \cdot 1$ & -0.014 & $-0.04,0.01$ & $0 \cdot 2$ & 0.002 & $-0.03,0.03$ & $0 \cdot 9$ \\
\hline Hispanic & 2239 & $8 \cdot 9$ & $90 \cdot 0$ & 0.074 & $0 \cdot 04,0 \cdot 11$ & $<0.001$ & 0.000 & $-0.02,0.02$ & $1 \cdot 0$ \\
\hline Other & 7511 & $30 \cdot 0$ & $86 \cdot 3$ & 0.002 & $-0.03,0.03$ & 0.9 & $-0 \cdot 013$ & $-0.03,-0.00$ & 0.05 \\
\hline Missing & 604 & $2 \cdot 4$ & & & & & & & \\
\hline \multicolumn{10}{|l|}{ Age } \\
\hline$\leq 19$ years & 2267 & $9 \cdot 0$ & $75 \cdot 8$ & Ref. & - & & Ref. & - & \\
\hline $20-24$ years & 6009 & $23 \cdot 7$ & $81 \cdot 9$ & 0.031 & $0.01,0.05$ & 0.004 & 0.004 & $-0.03,0.04$ & $0 \cdot 8$ \\
\hline $25-29$ years & 7317 & $28 \cdot 9$ & $85 \cdot 8$ & 0.031 & $0.01,0.05$ & 0.009 & 0.009 & $-0.02,0.04$ & 0.5 \\
\hline $30-34$ years & 6040 & $23 \cdot 9$ & $86 \cdot 8$ & 0.019 & $-0.00,0.04$ & $0 \cdot 1$ & 0.010 & $-0.02,0.05$ & 0.5 \\
\hline$\geq 35$ years & 3690 & $14 \cdot 6$ & $87 \cdot 1$ & $0 \cdot 021$ & $-0.00,0.05$ & $0 \cdot 09$ & $0 \cdot 014$ & $-0.03,0.05$ & $0 \cdot 4$ \\
\hline Missing & 4 & 0.02 & & & & & & & \\
\hline \multicolumn{10}{|l|}{ Education } \\
\hline$\leq 12$ years & 10978 & $43 \cdot 4$ & $77 \cdot 8$ & Ref. & - & & Ref. & - & \\
\hline$\geq 13$ years & 13718 & $54 \cdot 2$ & $89 \cdot 5$ & 0.097 & $0 \cdot 08,0 \cdot 12$ & $<0.001$ & 0.022 & $0.01,0.03$ & 0.003 \\
\hline Missing & 631 & $2 \cdot 5$ & & & & & & & \\
\hline \multicolumn{10}{|l|}{ Marital status } \\
\hline Married & 16526 & $65 \cdot 3$ & $88 \cdot 2$ & Ref. & - & & Ref. & - & \\
\hline Non-married & 8779 & $34 \cdot 7$ & $77 \cdot 2$ & -0.085 & $-0.11,-0.06$ & $<0.001$ & 0.013 & $-0.00,0.03$ & 0.09 \\
\hline Missing & 22 & 0.09 & & & & & & & \\
\hline \multicolumn{10}{|l|}{ On WIC } \\
\hline No & 14603 & $57 \cdot 7$ & $87 \cdot 5$ & Ref. & - & & Ref. & - & \\
\hline Yes & 10535 & $41 \cdot 6$ & $80 \cdot 1$ & -0.022 & $-0.04,0.01$ & 0.002 & 0.013 & $0.00,0.02$ & 0.03 \\
\hline Missing & 189 & $0 \cdot 8$ & & & & & & & \\
\hline \multicolumn{10}{|l|}{ Plurality } \\
\hline Singleton birth & 24421 & $96 \cdot 4$ & $84 \cdot 3$ & Ref. & - & & Ref. & - & \\
\hline Multiple birth & 905 & $3 \cdot 6$ & $86 \cdot 9$ & 0.022 & $-0.00,0.05$ & $0 \cdot 1$ & 0.010 & $-0.02,0.04$ & 0.5 \\
\hline Missing & 1 & $0 \cdot 00$ & & & & & & & \\
\hline \multicolumn{10}{|l|}{ Previous live births } \\
\hline None & 10611 & $41 \cdot 9$ & $86 \cdot 8$ & Ref. & - & & Ref. & - & \\
\hline 1 & 7681 & $30 \cdot 3$ & $83 \cdot 6$ & -0.045 & $-0.06,-0.03$ & $<0.001$ & -0.003 & $-0.02,0.01$ & $0 \cdot 7$ \\
\hline $2+$ & 6678 & $26 \cdot 4$ & $81 \cdot 3$ & -0.066 & $-0.08,-0.06$ & $<0.001$ & -0.003 & $-0.03,0.02$ & $0 \cdot 8$ \\
\hline Missing & 357 & $1 \cdot 4$ & & & & & & & \\
\hline
\end{tabular}

BFHI, Baby-Friendly Hospital Initiative; WIC, Special Supplemental Nutrition Program for Women, Infants, and Children; Ref., referent category. ${ }^{*}$ All models include year and hospital fixed effects.

points increase in exclusive breast-feeding among mothers with lower education attributed to BFHI accreditation are meaningful improvements at the population level, particularly because initial breast-feeding rates for this group were relatively low.

The present study substantially expands and extends a limited literature on the effectiveness of the BFHI in the USA. Over the past decade many birth facilities in the USA received BFHI accreditation, resulting in a natural experiment which we evaluated using PRAMS data from five states. Although randomized controlled trails are considered the gold standard for programme evaluation, the only such trial of the BFHI has been conducted outside the $\mathrm{USA}^{(18)}$. In the large Belarusian study, random allocation to the BFHI arm produced increases in breastfeeding duration and exclusivity, but it only included women who had already initiated breast-feeding ${ }^{(18)}$. The trial did not specifically address the impact of BFHI accreditation on breast-feeding outcomes. To our knowledge there is only one longitudinal evaluation of the BFHI in the USA, but it was limited to a before-after comparison in a single hospital ${ }^{(28-30)}$. Similar to the study of Boston Medical Center ${ }^{(28,30)}$, we found increases in breast-feeding initiation after hospitals received accreditation but less evidence for an impact on breastfeeding duration. Further research is needed to better understand how step \#10 of the BFHI, the only guideline for breast-feeding promotion after discharge, supports breast-feeding continuation and whether more efforts may be needed.

Although we were not able to explore potential mechanisms using these data, the 2011 mPINC survey confirmed that most birth facilities in the USA have some policies and practices that support breast-feeding ${ }^{(9)}$. Half of birth facilities reported complying with three to five recommended policies and practices of the BFHI and an additional $37 \%$ reported complying with six to eight recommendations ${ }^{(9)}$. In our sample, non-BFHI birth facilities were likely adopting similar practices over the study period. This observation suggests there was likely 
some contamination in our control group, meaning that our matched birth facilities may have implemented some hospital policies and practices supporting breast-feeding. Thus, our estimates of BFHI accreditation on breastfeeding outcomes may actually be lower than the true effects - as would be found by comparing birth facilities with no policies to those with the whole suite of policies required for BFHI accreditation. Since the PRAMS questionnaire did not routinely collect information on the BFHI breast-feeding practices that mothers experience, we were unable to examine whether it was BFHI accreditation itself or the number of breast-feeding practices that increased breast-feeding. Although hospitals may have been taking steps towards changing their policies in anticipation of accreditation, we found that the effects of these policy changes were not fully observed until after the hospitals received accreditation.

Consistent with the literature ${ }^{(5,7,8)}$, higher maternal education was one of the most important determinants of breast-feeding initiation. We also found that mothers with higher education were more likely to give birth in a BFHI-accredited hospital. These mothers may be more aware of Baby-Friendly accreditation, may choose to give birth there, or may live in areas with hospitals that are more conducive to becoming accredited. Although these mothers were more likely to attend BFHI facilities, they did not experience a further increase in breast-feeding rates beyond their already high levels. The mothers most affected by giving birth in Baby-Friendly hospitals were those with a high-school degree or less, suggesting that BFHI accreditation may be one element in decreasing socio-economic disparities in breast-feeding.

Strengths of our study included a longitudinal analysis over more than a decade, a control group of non-BFHI birth facilities, a large sample size of 25000 mothers from thirty-two birth facilities in five states and exploratory analyses to examine timing effects of the implementation of the BFHI. There are also several limitations of the study. The PRAMS survey does not provide a large sample of mothers from each hospital, so the mothers included may not be representative of those who gave birth in these hospitals. Mothers who participate in PRAMS receive questionnaires 4 months postpartum. There is no verification of infant feeding, although recall of breastfeeding has been shown to be reliable and valid up to 3 years postpartum ${ }^{(34)}$. Despite the possibility of misclassification, we have no reason to believe that delivering in a Baby-Friendly hospital would bias mothers' reporting; the PRAMS survey was designed as a more general surveillance tool and mothers surveyed were not aware of our study hypotheses. Since rates of breast-feeding initiation and duration, on average, were higher in these five states than the national average ${ }^{(2)}$, the BFHI has the potential for an even larger impact among low-educated women in states where breast-feeding rates are lower. 


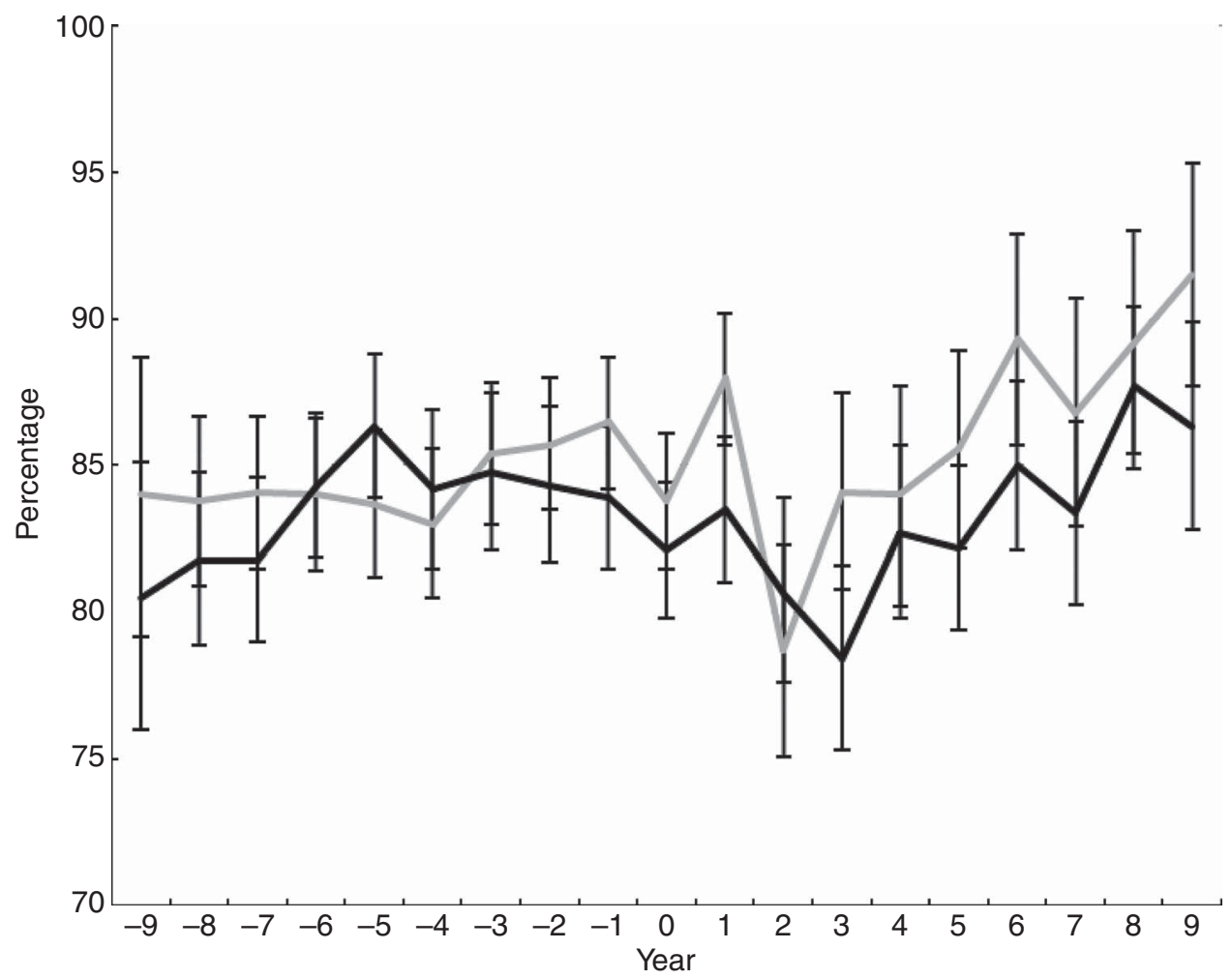

Fig. 2 Annual percentage of breast-feeding initiation with data centred on the date of accreditation for BFHI hospitals ( - ) and matched birth facilities (-); Pregnancy Risk Assessment Monitoring System, 1999-2009, five US states (AK, ME, NE, OH and WA). Values are percentages with their $95 \%$ confidence intervals represented by vertical bars. BFHI, Baby-Friendly Hospital Initiative

\section{Conclusions}

In 2012, only $6 \cdot 2 \%$ of US births occurred in BFHI facilities $^{(2)}$. We have shown that breast-feeding initiation increased among women with a high-school degree or less who delivered in hospitals that received BFHI accreditation. Our results provide support for increasing the number BFHI-accredited facilities to promote breastfeeding initiation, but more may be needed to sustain breast-feeding after discharge. Policy makers should continue to include the BFHI in strategies to help achieve public health goals to increase breast-feeding and reduce disparities $^{(5,14)}$

\section{Acknowledgements}

Sources of funding: This work was supported by grants from the National Institutes of Health (NIH) - NICHD R00HD068506 to S.S.H. and T32-AG000186 to the National Bureau of Economic Research and the NSF-IGERT programme, 'Multidisciplinary Program in Inequality \& Social Policy' at Harvard University (grant no. 0333403) to A.D.S. The content is solely the responsibility of the authors and does not necessarily represent the official views of the NIH. The NIH had no role in the design, analysis or writing of this article. Conflicts of interest: None. Ethics of buman subject participation: The Harvard School of Public Health Institutional Review Board reviewed the study and considered it exempt; each participating state approved the protocol. Authors' contributions: S.S.H. conceptualized and designed the study, participated in data collection, analysis and interpretation, drafted the initial manuscript, and approved the final manuscript as submitted. A.D.S. participated in data analysis and interpretation, critically reviewed and revised the manuscript, and approved the final manuscript as submitted. C.F.B. participated in data analysis and interpretation, reviewed and revised the manuscript, and approved the final manuscript as submitted. M.W.G. participated in data interpretation, critically reviewed and revised the manuscript, and approved the final manuscript as submitted. Acknowledgements: The authors would like to thank the following PRAMS working groups for the data and their assistance throughout this project: Alaska - Kathy Perham-Hester, MS, MPH; Maine - Tom Patenaude; Nebraska - Brenda Coufal; Ohio - Melissa VonderBrink, MPH; Washington - Linda Lohdefinck; and the Centers for Disease Control and Prevention PRAMS Team, Applied Sciences Branch, Division of Reproductive Health. The Ohio Department of Health $(\mathrm{ODH})$ data used in this study were obtained from the 
PRAMS Working Group, ODH. Use of these data does not imply ODH agrees or disagrees with any presentations, analyses, interpretations or conclusion.

\section{References}

1. Grummer-Strawn LM \& Shealy KR (2009) Progress in protecting, promoting, and supporting breastfeeding: 1984-2009. Breastfeed Med 4, Suppl. 1, S31-S39.

2. Centers for Disease Control and Prevention (2012) Breastfeeding Report Card - United States, 2012. http:// www.cdc.gov/breastfeeding/pdf/2012BreastfeedingReport Card.pdf (accessed November 2012).

3. American Academy of Pediatrics Section on Breastfeeding (2012) Breastfeeding and the use of human milk. Pediatrics 129, e827-e841.

4. Taveras EM, Gillman MW, Kleinman K et al. (2010) Racial/ ethnic differences in early-life risk factors for childhood obesity. Pediatrics 125, 686-695.

5. US Department of Health and Human Services (2011) The Surgeon General's Call to Action to Support Breastfeeding. Washington, DC: US DHHS.

6. Centers for Disease Control and Prevention (2013) Progress in increasing breastfeeding and reducing racial/ethnic differences - United States, 2000-2008 births. MMWR Morb Mortal Wkly Rep 62, 77-80.

7. DiGirolamo AM, Grummer-Strawn LM \& Fein SB (2008) Effect of maternity-care practices on breastfeeding. Pediatrics 122, Suppl. 2, S43-S49.

8. Centers for Disease Control and Prevention (2010) Racial and ethnic differences in breastfeeding initiation and duration, by state - National Immunization Survey, United States, 2004-2008. MMWR Morb Mortal Wkly Rep 59, 327-334.

9. Centers for Disease Control and Prevention (2011) mPINC results. http://www.cdc.gov/breastfeeding/data/ mpinc/results.htm (accessed July 2012).

10. World Health Organization \& UNICEF (1989) Promoting and Supporting Breastfeeding: The Special Role of Maternity Services. Geneva: WHO.

11. Baby-Friendly USA (2013) Home page. http://www. babyfriendlyusa.org (accessed March 2013).

12. Saadeh R \& Casanovas C (2009) Implementing and revitalizing the Baby-Friendly Hospital Initiative. Food Nutr Bull 30, 2 Suppl., S225-S229.

13. White House Task Force on Childhood Obesity (2010) Solving the problem of childhood obesity within a generation: The White House Task Force on Childhood Obesity Report to the President. http://www.letsmove.gov/ sites/letsmove.gov/files/TaskForce_on_Childhood_Obesity_ May2010_FullReport.pdf (accessed June 2012).

14. US Department of Health and Human Services (2010) Healthy People 2020 Objective Topic Areas and Page Numbers. http://healthypeople.gov/2020/topicsobjectives2020/pdfs/ HP2020objectives.pdf (accessed October 2012).

15. Centers for Disease Control and Prevention (2011) Hospital support for breastfeeding: preventing obesity begins in hospitals. http://www.cdc.gov/VitalSigns/BreastFeeding/ (accessed July 2012).
16. Venancio SI, Saldiva SR, Escuder MM et al. (2012) The Baby-Friendly Hospital Initiative shows positive effects on breastfeeding indicators in Brazil. J Epidemiol Community Health 66, 914-918.

17. Braun ML, Giugliani ER, Soares ME et al. (2003) Evaluation of the impact of the baby-friendly hospital initiative on rates of breastfeeding. Am J Public Health 93, 1277-1279.

18. Kramer MS, Chalmers B, Hodnett ED et al. (2001) Promotion of Breastfeeding Intervention Trial (PROBIT): a randomized trial in the Republic of Belarus. JAMA $\mathbf{2 8 5}$, 413-420.

19. Cattaneo A \& Buzzetti R (2001) Effect on rates of breast feeding of training for the baby friendly hospital initiative. BMJ 323, 1358-1362.

20. Merten S, Dratva J \& Ackermann-Liebrich U (2005) Do baby-friendly hospitals influence breastfeeding duration on a national level? Pediatrics 116, e702-e708.

21. Bartington S, Griffiths LJ, Tate AR et al. (2006) Are breastfeeding rates higher among mothers delivering in Baby Friendly accredited maternity units in the UK? Int $J$ Epidemiol 35, 1178-1186.

22. Brodribb W, Kruske S \& Miller YD (2013) Baby-friendly hospital accreditation, in-hospital care practices, and breastfeeding. Pediatrics 131, 685-692.

23. Merewood A, Mehta SD, Chamberlain LB et al. (2005) Breastfeeding rates in US Baby-Friendly hospitals: results of a national survey. Pediatrics 116, 628-634.

24. Rosenberg KD, Stull JD, Adler MR et al. (2008) Impact of hospital policies on breastfeeding outcomes. Breastfeed Med 3, 110-116.

25. Murray EK, Ricketts S \& Dellaport J (2007) Hospital practices that increase breastfeeding duration: results from a population-based study. Birth 34, 202-211.

26. Perrine CG, Scanlon KS, Li R et al. (2012) Baby-friendly hospital practices and meeting exclusive breastfeeding intention. Pediatrics 130, 54-60.

27. Declercq E, Labbok MH, Sakala C et al. (2009) Hospital practices and women's likelihood of fulfilling their intention to exclusively breastfeed. Am J Public Health 99, 929-935.

28. Philipp BL, Merewood A, Miller LW et al. (2001) Babyfriendly hospital initiative improves breastfeeding initiation rates in a US hospital setting. Pediatrics 108, 677-681.

29. Philipp BL, Malone KL, Cimo S et al. (2003) Sustained breastfeeding rates at a US Baby-Friendly hospital. Pediatrics 112, e234-e236.

30. Merewood A, Patel B, Newton KN et al. (2007) Breastfeeding duration rates and factors affecting continued breastfeeding among infants born at an inner-city US Baby-Friendly hospital. J Hum Lact 23, 157-164.

31. Centers for Disease Control and Prevention (2010) Pregnancy Risk Assessment Monitoring System (PRAMS). http://www.cdc.gov/prams/ (accessed May 2010).

32. World Health Organization (1981) International Code of Marketing Breast-milk Substitutes. Geneva: WHO.

33. Baum CF (2009) Locating nearest neighbors with Mata. In An Introduction to Stata Programming, pp. 327-331. College Station, TX: Stata Press.

34. Li R, Scanlon KS \& Serdula MK (2005) The validity and reliability of maternal recall of breastfeeding practice. Nutr Rev 63, 103-110. 